\title{
Not all nonwords are alike: Implications for reading development and theory
}

\author{
REBECCA TREIMAN \\ Wayne State University, Detroit, Michigan \\ USHA GOSWAMI \\ University of Cambridge, Cambridge, England \\ and \\ MAGGIE BRUCK \\ Learning Centre of Quebec and McGill University \\ Montreal, Quebec, Canada
}

\begin{abstract}
Three experiments were designed to examine children's and adults' ability to pronounce consonant-vowel-consonant (CVC) nonsense words. Some of the nonwords, like tain and goach, shared their VC unit with a number of real words. Other nonwords, like goan and taich, shared their VC unit with few or no real words. Pooling across items, the very same grapheme-phoneme correspondences occurred in the two types of nonwords. First graders, good and poor third grade readers, and adults all performed better on the nonwords with the more common VC units than on the nonwords with the less common VC units. Although readers appeared to use VC units in the pronunciation of nonwords, we did not find evidence for use of initial CV units. Implications of the results for reading development, dyslexia, and models of nonword pronunciation are discussed.
\end{abstract}

To become literate in a language such as English, children must grasp the alphabetic principle. They must realize that printed words are not arbitrary sequences of letters that can only be memorized by rote. Rather, the letters and groups of letters in printed words bear some correspondence to the phonemes in spoken words. Thus, a major task for young readers is to learn about the relationships between spellings and sounds. Children's knowledge of spelling-sound rules is often assessed by having them pronounce nonwords-orthographically acceptable but meaningless strings of letters. Children who can accurately pronounce nonwords, it is assumed, must be employing correspondences between spellings and sounds. Since the children have not previously seen the letter strings, they cannot have memorized their pronunciations.

Although nonwords are widely used in studies of children's reading, there is controversy about how children determine their pronunciations. The traditional view (e.g.,

This research was supported by NICHD Grants HD20276 and HD00769 to R. Treiman, a National Health and Welfare Scholar Award to M. Bruck, Grant OGP0001181 from the National Sciences and Engineering Research Council to M. Bruck, and Grant EQ-4246 from FCAR to M. Bruck. Thanks to Jennifer Gross, Michelle Hadley, Kent Kohtz, and Patrick Lavery for their assistance with the experiments, and to Sally Andrews and two anonymous reviewers for their comments. Some of the data reported here were presented at a meeting of the American Educational Research Association (Boston, April 1990). Correspondence and reprint requests may be directed to Rebecca Treiman, Psychology Department, Wayne State University, 71 W. Warren Ave., Detroit, MI 48202, or $r_{-}$treiman\%wayne-mts@um.cc.umich.edu. that of M. Coltheart, 1978) is that, given a nonword like tain, children (and adults) segment it into the units $t, a i$, and $n$. These orthographic units are called graphemes, where a grapheme is defined as a letter or group of letters that corresponds to a single phoneme. Children apply a series of grapheme-phoneme correspondence rules, or GPCs, to translate the orthographic representation into a phonemic one. In our example, the GPCs are $t \rightarrow / t /$, ai $\rightarrow / \mathbf{e} /$, and $n \rightarrow / \mathbf{n} /$. (See the Appendix for a key to the notation.) This GPC view has two important consequences. First, children use rules at the level of graphemes and phonemes rather than rules that involve larger units. Second, children are not affected by the similarity between the nonword tain and real words such as tail and main.

Recent evidence, however, does not support a simple version of the GPC view. For example, Laxon, V. Coltheart, and Keating (1988) compared children's ability to pronounce "friendly" and "unfriendly" nonwords. The friendly nonwords had many neighbors, defined in this study, following $M$. Coltheart, Davelaar, Jonasson, and Besner (1977), as words that differed from the nonword by one letter in the same position. For example, the neighbors of flad include glad, fled, and flat. Unfriendly nonwords, such as blid, had relatively few neighbors. The children performed better on the friendly nonwords than on the unfriendly ones. The effect of friendliness on nonword pronunciation was found for all reading levels examined ( $71 / 2$ to 10 years). In addition, the children were more likely to misread friendly nonwords as real words than to misread unfriendly nonwords as real words. These results suggest that children are affected by the similar- 
ity between nonwords and real words, contrary to the implication of the simple GPC view.

If children use their knowledge of real words to help them pronounce nonwords, what sorts of real-word neighbors are influential? For consonant-vowel-consonant (CVC) nonwords, does the neighborhood include words that share the $\mathrm{CV}, \mathrm{VC}$, or $\mathrm{CC}$ of the nonword, as assumed by Laxon et al. (1988), or does it only or primarily include words that share the VC, as assumed by Glushko (1979) and others? Recent findings with adults suggest that VC neighbors have a stronger influence on nonword pronunciation than do CV neighbors (Taraban \& McClelland, 1987; Treiman \& Zukowski, 1988). Goswami (1986) suggested that this holds true for children as well. In Goswami's study, children received a word like beak as a "clue." Given the clue word, children with reading ages of between about 6 and $71 / 2$ could often pronounce a nonword like neak, which shares the $\mathrm{V}$ and final $\mathrm{C}$ with the clue word. There was less benefit for nonwords like beal, which share the clue word's initial C and V. A limitation of Goswami's study is that it does not indicate whether VC units would be superior to CV units when children must pronounce a new word without receiving an explicit clue, a situation that is more typical of real reading.

In the present study, children were asked to read nonwords aloud without being specifically told to use analogies. We predicted that performance would be influenced by the degree to which the VC unit of the nonword occurred as a VC unit among the real words of the language. $\mathrm{CV}$ units, we hypothesized, would be less influential. One reason for supposing that $\mathrm{VC}$ units would be more important than $\mathrm{CV}$ units is that VC units correspond to a natural phonological constituent of the spoken syllablethe rime. Linguistic and psycholinguistic evidence (see Treiman, 1988, for a review) suggests that spoken syllables contain two primary units. The onset is the initial consonant or consonant cluster (e.g., the /t/ of /ten/); the rime is the vowel and any following consonants (e.g., the /en/ of / ten/). Because many young children can divide spoken syllables into onsets and rimes (e.g., Treiman \& Zukowski, in press), children may divide printed syllables into units that correspond to onsets and units that correspond to rimes. Another reason for expecting children to use VCs stems from the nature of English orthography. In English, the consonant grapheme that follows a vowel grapheme sometimes influences the vowel's pronunciation. Only rarely does the preceding consonant systematically affect the pronunciation of the vowel. As children become aware of this characteristic of English, they may increasingly rely on VC units.

In Experiment 1, we compared children's ability to pronounce two types of nonwords, labeled $\mathrm{H}$ (or high) nonwords and L (or low) nonwords. All the nonwords contained a consonant grapheme followed by a vowel grapheme followed by another consonant grapheme. The graphemes were either one or two letters long. The nonwords were arranged in groups of four-for example, tain $(\mathrm{H})$, goan $(\mathrm{L})$, goach $(\mathrm{H})$, and taich $(\mathrm{L})$. Within a group, the same graphemes occurred in the $\mathrm{H}$ and $\mathrm{L}$ items. Thus, if children rely only on GPCs to pronounce nonwords, performance on the $\mathrm{H}$ and $\mathrm{L}$ items should be indistinguishable. However, the graphemes were arranged so that the VC units of the $\mathrm{H}$ items (ain and oach in the example) were more frequent in real words than those of the $\mathrm{L}$ items (oan and aich), according to three measures. The first measure was the number of one-syllable words in a computerized dictionary (Wordfind Version 2.2, Software Heaven, 1984) in which the VC corresponded to the rime of the spoken word. The second measure was the number of these words from the computer dictionary that also occurred in Carroll, Davies, and Richman (1971), a collection of words in reading materials designed for children in the third through ninth grades. The third measure was the summed frequency of the words in question in Carroll et al. (1971). If experience with real words like main and rain helps children to pronounce nonwords like tain, then children should perform better on the $\mathrm{H}$ nonwords than on the $\mathrm{L}$ nonwords.

The frequencies of the initial CVs, using three measures analogous to those just discussed for VCs, were very similar for the $\mathrm{H}$ and $\mathrm{L}$ nonwords. Thus, if children use initial CV units as a basis for nonword decoding, they should perform equally on the two types of nonwords. ${ }^{1}$

None of the stimuli contained VCs like aid, which have an atypical pronunciation in a one-syllable real word that might be familiar to a child (said). Initial CVs with inconsistent pronunciations (e.g., pi, which is pronounced differently in pint than in pin and pill) were also excluded. Thus, all our nonwords would be classified as regular and consistent.

In addition to the nonword pronunciation test, the children were given a test of grapheme-phoneme knowledge and a real-word reading test. In the grapheme-phoneme test, the children were shown the individual graphemes that were used in the nonword stimuli (e.g., $t, a i, n)$ and were asked to give their sounds. In the real-word reading test, the children were asked to pronounce words like main that contained the same VCs as the nonwords. This test was designed to determine whether the children knew some of the real words that could potentially help them to pronounce the nonwords.

\section{EXPERIMENT 1}

\section{Method}

Stimuli. The stimuli included 48 nonwords. As described above, the stimuli were designed in groups of 4 that used the same graphemes, each group containing two $\mathrm{H}$ nonwords and two L nonwords. Each nonword was printed on a $4 \times 6$-in. card, using primary size lowercase letters. For the test of grapheme-phoneme knowledge, each of the 10 vowel graphemes and 18 consonant graphemes in the nonword stimuli was printed on a $3 \times 4$-in. card in primary size lowercase letters. For the real-word reading test, we chose the most frequent one-syllable word in Carroll et al. (1971) that had each of the VCs in the nonword stimuli. Some of the VCs for the $\mathrm{L}$ items were not included, since no monosyllabic real words contained them. The real-word reading test contained 30 items. The words were printed in a random order on a single sheet of paper 
in primary size upper- and lowercase letters. A list of the nonword and word stimuli appears in the Appendix. The Appendix also indicates the pronunciation that was counted as correct for each nonword, which was, as in other studies of nonword reading, the pronunciation given by the major grapheme-phoneme correspondence rules of Venezky (1970).

Procedure. Each child was tested individually. The test of grapheme-phoneme knowledge was given first. Here, the child was first asked to name the letter or letters on each card. The experimenter corrected any wrong answers. The child was then asked to give the sound of the grapheme. The order of the cards was randomized for each subject. The reading subtest of the Wide Range Achievement Test-Revised (WRAT-R) (Jastak \& Wilkinson, 1984) was given next. The nonword reading test was then given. The child was told that he or she would be asked to read some made-up words and should pronounce each one however he or she thought best. Responses were transcribed by a phonetically trained experimenter, and no feedback was given. The order of the nonwords was randomized for each child. The real-word reading test was given last. One first grader did not take this test, due to absence from school. In most cases, the tests were presented in two separate sessions several days apart.

Subjects. Twenty-nine first graders from a U.S. public school participated. The school served a middle class, suburban population. The children were tested during the last month of the first grade year. Their mean age was 7 years, 3 months (range 6,6-7,10). On the WRAT-R, the children's average reading score corresponded to a beginning second grade reading level. The children's teacher primarily used a "whole language" approach to the teaching of reading. This instruction was supplemented with a phonics book that stressed grapheme-phoneme correspondences rather than "word families" such as cat, hat, and bat.

\section{Results}

Before presenting the main results on children's pronunciations of $H$ and $L$ nonwords, several subsidiary findings must be mentioned. First, the children almost always knew the names of the letters on the grapheme-phoneme test (mean proportion correct, .97). Their knowledge of the graphemes' sounds was somewhat poorer (mean proportion correct, .78). On the real-word reading test, the mean proportion correct was .61 . This was significantly better than the .47 correct on the nonwords that had the same VCs as the real words [by subjects, $t(27)=$ 6.64 ; by stimuli, $t(29)=12.97 ; p<.05$ for this and all other statistical tests reported in this paper unless otherwise stated]. The difference suggests that the children were familiar with a number of real words that could potentially help them to pronounce the nonwords. Finally, because we used the Carroll et al. (1971) word frequency norms to help select the $\mathrm{H}$ and $\mathrm{L}$ nonwords for this study, we should note that performance on our word reading test correlated with word frequency in Carroll et al. $(r=.56)$. Thus, although the Carroll et al. norms are somewhat dated, and although they are based on reading materials for third through ninth grade students, they have some validity for the first grade pupils in this study.

The primary results of this study concern the nonword pronunciation test. As is shown in the first row of $\mathrm{Ta}$ ble 1 , the first graders did better on the $\mathrm{H}$ nonwords than on the $\mathrm{L}$ nonwords. The difference was significant by subjects $[t(28)=4.07]$ and by groups of stimuli $[t(11)=$ 3.69]. Because the $H$ and $L$ nonwords have the same
Table 1

Results of Nonword Pronunciation Test

\begin{tabular}{lcc}
\hline \multicolumn{1}{c}{ Group } & $\begin{array}{c}\mathrm{H} \\
\text { Nonwords }\end{array}$ & $\begin{array}{c}\mathrm{L} \\
\text { Nonwords }\end{array}$ \\
\hline First graders, proportion correct & .49 & .41 \\
Poor third grade readers, proportion correct & .56 & .39 \\
Good third grade readers, proportion correct & .90 & .79 \\
Adults, proportion correct & .93 & .81 \\
Adults, reaction time (in milliseconds) & & \\
$\quad$ for correct responses & 552 & 563 \\
\hline
\end{tabular}

GPCs, and because their CV units are of similar frequencies, the better performance on $\mathrm{H}$ nonwords than on $\mathrm{L}$ nonwords suggests that first graders use VC units in nonword pronunciation.

Recall that the first graders of Experiment 1 were tested near the end of the school year, and that they performed, on the average, at a beginning second grade reading level. However, a superiority for $\mathrm{H}$ nonwords over $\mathrm{L}$ nonwords was found even among the 15 children who scored at the first grade reading level on the WRAT-R. For these children, the mean proportion correct on $\mathrm{H}$ nonwords was .32 and the mean proportion correct on $L$ nonwords was .26. The difference was significant by subjects $[t(14)=$ $2.26]$ and by groups of stimuli $[t(11)=1.81]$.

To further study the roles of GPCs, VC units, and CV units in the children's pronunciation of nonwords, we performed multiple regression analyses. These analyses represented an attempt to predict the proportion of correct responses to each nonword from several different predictors. The first predictor reflected the children's knowledge of the GPCs in the nonword. With sug, for instance, children always gave the correct sound of $s$ in the test of grapheme-phoneme knowledge. The proportion correct on $u$ was .59 and the proportion correct on $g$ was .62. Thus, the expected proportion of correct responses to sug, solely on the basis of children's knowledge of its GPCs, was $1.0 \times .59 \times .62$, or .37 . The second predictor of nonword pronunciation accuracy was a measure of the frequency of the nonword's VC unit. The third predictor was a measure of the frequency of the nonword's CV unit. We carried out three separate analyses, each involving a different measure of $\mathrm{VC}$ and $\mathrm{CV}$ frequency. The first analysis involved the number of words in the computerized dictionary, the second involved the number of those words in Carroll et al. (1971), and the third involved the summed frequency of the words in Carroll et al. (1971). All three regressions explained a significant proportion of the variance in nonword reading - .39 in Analysis 1, .40 in Analysis 2, and .34 in Analysis 3.

Partial correlation analyses were performed to determine whether each of the predictors made a significant contribution once the effects of the others were statistically taken into account. In all three analyses, the partial correlation for GPCs was significant. The contribution of VC frequency was also reliable. However, CV frequency did not make a positive contribution in any of the 
Table 2

Correlations between Children's Grapheme-to-Phoneme Correspondence Knowledge and Other Measures

\begin{tabular}{lccc}
\multicolumn{1}{c}{ Group } & $\begin{array}{c}\text { Real } \\
\text { Words }\end{array}$ & $\begin{array}{c}\text { H } \\
\text { Nonwords }\end{array}$ & $\begin{array}{c}\text { L } \\
\text { Nonwords }\end{array}$ \\
\hline First graders & $.56^{*}$ & $.61^{*}$ & $.73^{*}$ \\
Poor third grade readers & .12 & .36 & .29 \\
Good third grade readers & .13 & .01 & $.45^{*}$ \\
\hline
\end{tabular}

* Significant.

analyses once the other variables were statistically controlled. The null results for $\mathrm{CV}$ frequency were obtained even though the variance of CV frequency was at least as great as the variance of $\mathrm{VC}$ frequency according to all three of the measures.

Table 2 shows the correlations between the individual children's knowledge of GPCs and their performance on the real-word reading test and the $\mathrm{H}$ and $\mathrm{L}$ nonwords. The results are based on the 28 children who took all the tests. Although all three correlations were significant, the correlation between GPC knowledge and L nonword reading was significantly higher than the correlations between GPC knowledge and $\mathrm{H}$ nonword reading $[t(25)=1.77]$ and GPC knowledge and real-word reading $[t(25)=$ 2.16]. Knowledge of GPCs seems to be particularly beneficial for the decoding of $\mathrm{L}$ nonwords. The fact that performance on $\mathrm{H}$ nonwords and performance on $\mathrm{L}$ nonwords correlated differently with GPC knowledge provides further evidence that children do not read all nonwords in the same way.

Analyses of children's errors on the nonword reading task showed that the most common single type of error on both $\mathrm{H}$ and $\mathrm{L}$ items was to mispronounce the vowel while correctly pronouncing both consonants. Such errors constituted .59 of the total. Following Laxon et al. (1988), we also examined lexicalizations, or errors on nonwords that produced real words. Table 3 shows the proportion of lexicalization errors on $\mathrm{H}$ and $\mathrm{L}$ nonwords.

\section{Discussion}

The main finding of this experiment is that first graders pronounced $\mathrm{H}$ nonwords significantly more accurately than $L$ nonwords. The two types of nonwords had the same GPCs, and the frequencies of their initial CV units were similar. The children's better performance on the $\mathrm{H}$ nonwords must be a reflection of their greater familiarity with the $\mathrm{VC}$ units of the $\mathrm{H}$ nonwords. Thus, an $\mathrm{H}$ nonword like tain is relatively easy to pronounce because of the existence of real words like main, rain, and train. An $\mathrm{L}$ nonword like goan is more difficult to pronounce be-

Table 3

Proportions of Errors on Nonwords That Produced Real Words

\begin{tabular}{lcc}
\hline \multicolumn{1}{c}{ Group } & H Nonwords & L Nonwords \\
\hline First graders & .36 & .32 \\
Poor third grade readers & .37 & .34 \\
Good third grade readers & .52 & .24 \\
Adults & .50 & .27 \\
\hline
\end{tabular}

cause relatively few real words end with oan. In the General Discussion, we will consider how these findings may be interpreted within models of nonword reading and theories of reading development.

The results of the regression and partial correlation analyses support the idea that VC units play a role in the pronunciation of nonwords. As the frequency of the nonword's VC increased, so did the children's correct pronunciations of the nonword. The number of different words that contained a VC unit predicted performance slightly better than did the summed frequencies of those words.

Although VC units appeared to influence nonword reading, CV units did not appear to do so. There was no significant association between the frequency of a nonword's initial CV and the children's ability to pronounce the nonword. Additional support for this conclusion awaits the results of a study that manipulates $\mathrm{CV}$ frequency while equating for $\mathrm{VC}$ frequency, which was not done in the present study.

Do grapheme-phoneme correspondences also play a role in children's pronunciation of nonwords? Some role for GPCs is suggested by the finding that GPC knowledge contributed significantly to nonword reading, above and beyond the contribution of VC frequency. However, the children's knowledge of GPCs was more closely tied to their ability to pronounce $\mathrm{L}$ nonwords than to their ability to pronounce $\mathrm{H}$ nonwords or real words. Thus, children who are trying to decode an L nonword like goan may be forced to use GPCs because few real words end with oan. When decoding an $\mathrm{H}$ nonword like tain, correspondences at the level of single graphemes and single phonemes may be less important, since children can rely on the easier strategy of using VC units.

In Experiment 2, we examined whether the differences between $\mathrm{H}$ and $\mathrm{L}$ nonwords that were found for first graders would also occur in older children. We tested good and poor third grade readers.

\section{EXPERIMENT 2}

\section{Method}

Stimuli and Procedures. The stimuli and procedures for Experiment 2 were identical to those for Experiment 1.

Subjects. The subjects were 30 third graders from a Canadian public school that served a middle class, suburban population. The children were tested during the first half of the school year. They averaged 8 years, 7 months in age (range: $7,8-10,1$ ). The children had been taught by a whole language approach with little supplemental phonics. Fifteen good readers and 15 poor readers were selected according to the following criteria: Good readers performed at or above the 68th percentile on the WRAT-R reading subtest, with a minimum raw score of 66 , which corresponds to a reading level at the end of third grade. Also, their performance on the WRAT-R spelling test was at least at grade level. The poor readers performed at or below the 30th percentile on the WRAT-R reading subtest. The maximum raw reading score for this group was 56 , or end of second grade. To be included in the poor reader group, a child's WRAT-R spelling score also had to be below grade level. The average WRAT-R reading level for the good readers was beginning of fifth grade; the average WRAT-R reading level for the poor readers was middle of second grade. 


\section{Results}

On the grapheme-phoneme test, all children knew the names of all the letters. The proportion of sounds correct was .91 for the good readers and .79 for the poor readers, a significant difference [by subjects, $t(28)=3.66$; by stimuli, $t(27)=3.98]$.

On the real-word reading test, the good readers again outperformed the poor readers, averaging .97 correct responses as compared with .74 for poor readers [by subjects, $t(28)=7.51$; by stimuli, $t(29)=5.76$ ]. Both groups did better on the real words than on the nonwords that shared the real words' VCs [good readers, $t(14)=4.32$ by subjects, $t(29)=3.87$ by stimuli; poor readers, $t(14)=$ 6.83 by subjects, $t(29)=6.59$ by stimuli]. Performance improved with the frequency of the word in Carroll et al. (1971) ( $r=.49$, pooling over good and poor readers), helping to validate our use of these norms in stimulus selection.

The most important results, of course, concern performance on the nonword pronunciation test. The second and third rows of Table 1 show the mean proportions of correct responses on $\mathrm{H}$ and $\mathrm{L}$ nonwords for the two groups of third graders. Analyses of variance with the factors nonword type (H vs. L) and reader group (good vs. poor) revealed that the children did better on $\mathrm{H}$ nonwords than on L nonwords [by subjects, $F(1,28)=47.29$; by groups of stimuli, $F(1,11)=14.61]$. Also, good readers outperformed poor readers [by subjects, $F(1,28)=102.36$; by groups of stimuli, $F(1,11)=164.01]$. The interaction between nonword type and reader group was not significant in the analysis by subjects $[F(1,28)=2.45, p>.10]$ but was significant in the analysis by groups of stimuli $[F(1,11)=7.77]$. As the results in Table 1 show, the trend was for poor readers to show a larger difference between $\mathrm{H}$ and $\mathrm{L}$ nonwords than good readers.

Multiple regression analyses were performed to predict the proportion of correct responses to each nonword from the children's knowledge of the GPCs in the nonword, the frequency of the nonword's $\mathrm{VC}$, and the frequency of the nonword's CV. As for Experiment 1, we carried out three regression analyses, each involving a different measure of VC and CV frequency. All three regressions explained a significant proportion of the variance in nonword reading: .38 in the analysis involving number of words in the computerized dictionary, .38 in the analysis involving number of words in Carroll et al. (1971), and .34 in the analysis involving summed frequency in Carroll et al. (1971). Partial correlation analyses showed that GPC knowledge made a significant contribution to the prediction when the other variables were held constant. The contribution of VC frequency was also reliable. However, $\mathrm{CV}$ frequency made no significant contribution when the other factors were statistically controlled. This pattern of results replicates the pattern in the first grade data.

The regression and partial correlation results reported above are based on the pooled data for good and poor readers. Analyses were also carried out for each group separately. The results were very similar to those described for the group as a whole.

Table 2 shows the correlations between the children's knowledge of GPCs and the other measures. These results must be interpreted with caution because of the relatively small number of children in each group. For poor third grade readers, none of the correlations was significant. For good third grade readers, only the correlation between GPC knowledge and L nonword reading was reliable; this correlation significantly exceeded the correlation between GPC knowledge and $\mathrm{H}$ nonword reading $[t(12)=2.85]$.

We may compare the data for the poor third grade readers of Experiment 2 to the data for the first graders of Experiment 1. Although the poor third grade readers were about a year and a half older than the first graders, the two groups' performances on the WRAT-R reading subtest, the sound portion of the grapheme-phoneme test, and the real-word reading test were statistically indistinguishable by two-tailed $t$ tests (although there was a nonsignificant trend for the poor third grade readers to perform better on the WRAT-R and the real-word reading test). Given this approximate match in real-word reading ability, how did the two groups compare in nonword reading? Analyses of variance with the factors nonword type (H vs. L) and reader group (poor third grade vs. first grade) showed no effect of reader group. As expected from previous findings, there was a significant effect of nonword type [by subjects, $F(1,42)=14.50$; by groups of stimuli, $F(1,11)=27.10$ ]. Children performed better on $\mathrm{H}$ nonwords than on $\mathrm{L}$ nonwords. We are most interested in the possibility of an interaction between nonword type and reader group. The analysis by subjects yielded a significant interaction $[F(1,42)=4.92]$, but the analysis by groups of stimuli did not $[F(1,11)=3.18$, $p=.10]$. As the data in Table 1 show, the trend was for poor third grade readers to show a larger deficit on $\mathrm{L}$ nonwords relative to $\mathrm{H}$ nonwords than the first graders.

Finally, we analyzed children's errors in the nonword reading task. As in Experiment 1, mispronunciations of the vowel were common on both $\mathrm{H}$ and $\mathrm{L}$ nonwords. The proportion of nonword errors in which children correctly pronounced both consonants but mispronounced the vowel was .54 for both good and poor readers. Data on lexicalization errors are shown in Table 3.

\section{Discussion}

The most important result of Experiment 2 can be simply stated: Differences between $\mathrm{H}$ and $\mathrm{L}$ nonwords are not confined to first graders. They occur, as well, among third grade children performing at the second grade reading level and third grade children performing at the fifth grade reading level. Thus, VC units continue to be important at higher stages of reading skill.

As in Experiment 1, we obtained evidence for one particular type of larger unit-VCs. We did not find evidence that children use initial $\mathrm{CV}$ units when assembling the 
pronunciations of nonwords. Children also appeared to use GPCs in nonword pronunciation. In the General Discussion, we will consider how these results fit into models of nonword reading and theories of reading development.

Of the three groups of children tested in Experiments 1 and 2, the poor third grade readers appeared to show the largest difference between $\mathrm{H}$ nonwords and $\mathrm{L}$ nonwords (see Table 1). This trend suggests that poor readers have more severe problems at the level of grapheme-phoneme correspondences than they do at the level of larger units. However, because the trend was not significant in both analyses by subjects and analyses by stimuli, we cannot confidently conclude that it is real. This issue will be considered further in the General Discussion.

It is noteworthy that even the good third grade readers, who performed at the fifth grade level, did not do perfectly on our nonword reading test. In light of this finding, in Experiment 3 we asked whether adults might also show a difference between $\mathrm{H}$ and $\mathrm{L}$ nonwords. In Experiment 3 , we measured college students' latencies and errors to pronounce the two types of nonwords.

\section{EXPERIMENT 3}

\section{Method}

Stimuli. The 48 nonwords from Experiments 1 and 2 were used again in Experiment 3. There were also 5 practice nonwords.

Procedure. Each stimulus was presented in lowercase letters at the center of an IBM monitor (Model 5154) attached to an IBM AT computer. The interstimulus interval was $1 \mathrm{sec}$, and each nonword remained on the screen until the subject pronounced it. A realtime clock calculated the response time in milliseconds from the time at which the nonword appeared on the screen to the time at which the subject began to speak into the microphone. The subjects were told that they should pronounce the nonwords as quickly as possible without making any mistakes. The five practice stimuli were presented first, followed by the experimental stimuli. The order of the experimental stimuli was randomized.

Subjects. Fifteen students from McGill University served as paid participants. All were from English-speaking backgrounds.

\section{Results and Discussion}

Table 1 shows the proportion of correct responses and mean latency for correct responses for $\mathrm{H}$ and $\mathrm{L}$ nonwords. The subjects made significantly more correct responses to $\mathrm{H}$ nonwords than to $\mathrm{L}$ nonwords [by subjects, $t(14)=$ 5.28; by groups of stimuli, $t(11)=3.97]$. Although the subjects tended to pronounce $\mathrm{H}$ nonwords more quickly than $\mathrm{L}$ nonwords, the difference in latencies did not reach significance [by subjects, $t(14)=1.71, p<.06$, onetailed; by groups of stimuli, $t(11)=1.44, p<.10$, onetailed]. Thus, when required to pronounce nonwords quickly and accurately, college students-like first and third grade children-make more errors on L nonwords than on $\mathrm{H}$ nonwords, while showing no evidence of a speed/accuracy tradeoff.

We carried out multiple regression analyses to predict the proportion of correct responses and the latency to each nonword from the frequency of the nonword's VC and CV units. (GPC knowledge was not included in the anal- yses, since adults' knowledge of the GPCs was assumed to be perfect.) For errors, the proportion of variance explained was .14 in the analysis done with the number of words in the computerized dictionary, .13 in the analysis done with the number of words in Carroll et al. (1971), and .11 in the analysis done with the summed frequency in Carroll et al. (1971). Although the proportion of variance explained was low in all three cases, it was significant in Analyses 1 and 2 and approached significance in Analysis $3(p<.08)$. Moreover, the partial correlation for VC frequency was significant in all three analyses, indicating that correct responses increased as more real words shared the nonword's VC. CV frequency did not contribute significantly in any of the analyses. None of the multiple regression analyses predicted a significant proportion of the variance in latencies.

The adults' errors on both $\mathrm{H}$ and $\mathrm{L}$ nonwords, like the children's, often involved mispronunciation of the vowel. The proportion of errors in which the vowel was misread but both consonants were correctly pronounced was .66 . Data on lexicalization errors appear in Table 3.

\section{GENERAL DISCUSSION}

The major finding in these experiments is that all nonwords are not read in the same manner. The nonwords used here all contained a consonant grapheme followed by a vowel grapheme and another consonant grapheme; the $\mathrm{H}$ nonwords and $\mathrm{L}$ nonwords contained the same graphemes. All the nonwords would be classified as regular and consistent. Nonetheless, people were better at pronouncing the $\mathrm{H}$ nonwords-the nonwords that shared their VCs with many real words - than they were at pronouncing the L nonwords-those that shared their VCs with few or no real words. This difference held for all groups of subjects tested, including first graders, good and poor third grade readers, and college students.

In addition to the different levels of performance on the two types of nonwords, there were other signs that the $\mathrm{H}$ and $\mathrm{L}$ nonwords were not read in the same way. For one thing, subjects tended to make more lexicalization errors on the $\mathrm{H}$ nonwords than on the $\mathrm{L}$ nonwords. This tendency was strongest for the more skillful readers (see Table 3), which could be taken to suggest that analogies or larger units become more important with increasing levels of reading skill. Also, for two of the three groups of children in this study, knowledge of grapheme-phoneme correspondences correlated significantly more highly with performance on $L$ nonwords than with performance on $\mathrm{H}$ nonwords.

Because children (and adults) perform differently on different types of nonwords, tests of nonword reading are not as simple as they might first appear. As our results testify, different levels of performance, different error types, and even different patterns of correlation between nonword reading and other abilities can be obtained by using different types of nonwords. Thus, we cannot assume that all nonword reading tests provide the same clean 
measure of children's knowledge of spelling-sound correspondences. If the test includes a high proportion of nonwords like tain-nonwords that share their VCs with common real words-children may do well without necessarily being able to translate from individual graphemes to individual phonemes.

As an example of the problems that may arise from assuming that one nonword reading test is interchangeable with another, consider a current debate in the field of dyslexia. The issue is whether dyslexics are worse than younger normal children of the same reading level in their ability to pronounce nonwords. Such a difference has been taken to mean that dyslexics are deficient in phonological skills and that their phonological deficit may cause their reading problems. Although many studies have reported dyslexics to be poorer in nonword reading than reading-level matched controls are, this result has not been found in other studies (for a review, see Olson, Wise, Conners, \& Rack, 1990). One factor that might contribute to the discrepant findings concerns the type of nonword used. Studies done with nonwords that share their VCs with many real words, like the $H$ nonwords of the present study, may yield small or no differences between dyslexics and younger normal children. For example, Treiman and Hirsh-Pasek (1985) used nonwords such as gome, which ends like home, dome, come, and other real words. In this study, dyslexics were not worse than younger normal readers in their ability to pronounce the nonwords. On the other hand, studies done with nonwords of the $\mathrm{L}$ variety may be more likely to yield differences between dyslexics and younger reading-level matched controls.

The present experiments did not allow us to test the hypothesis that differences between dyslexics and readinglevel matched controls are greater for $\mathrm{H}$ nonwords than for $\mathrm{L}$ nonwords. Not all of the third grade poor readers of Experiment 2 would fit the standard definition of dyslexia. These poor readers were not all two or more years below grade level in reading, and no IQ tests were given. Also, the reading-level match in this study was not as close as it could have been. The trend, however, was for the poor third grade readers to do better than the first graders on the $\mathrm{H}$ nonwords and slightly worse on the $\mathrm{L}$ nonwords. If future studies with carefully chosen groups of dyslexics and reading-level matched controls were to reveal a clear interaction between group and nonword type, we might be able to suggest that dyslexics have particularly severe problems in the use of grapheme-phoneme correspondences.

In addition to their implications for theories of dyslexia, our results have implications for theories of reading development. Marsh, Friedman, Welch, and Desberg (1981) and Frith (1985) claim that reading development proceeds through a sequence of stages. At first, children decode unfamiliar words on a grapheme by grapheme basis. Only later-not until the middle years of childhood, according to Marsh et al. (1981)-do children use analogies and larger units. Our data show that if there is a stage at which children rely only on GPCs, it must be short. By the end of the first grade, students reading at the first grade level were already using VC units. They did so even though the phonics instruction that they received stressed GPCs.

Why do even beginning readers use VC units? If readers use VC units only because they have observed that vowels and following consonant graphemes are pronounced more consistently than initial consonants plus vowels, the use of VC units should emerge slowly, as children become familiar with the nature of the English writing system. The early use of VC units is more compatible with the developmental model put forward by Goswami and Bryant (in press). In this model, children's experiences with rhyme help them to recognize onset and rime units when they begin to read. Children learn that rhyming words often share the same spelling patterns for their rimes, and so make inferences about the sounds of new words on the basis of their spellings. Our data support Goswami and Bryant's claim that units like ain are important from the beginning of reading development, although facility in using these units to make analogies may improve with increasing reading skill. Although our data are consistent with the idea that VC units in printed words derive their importance from rime units in spoken words, the results are not conclusive on this point. Because we used only monosyllabic stimuli, it could be argued that the units consist of everything in the word after the first consonant(s). Research with words of more than one syllable will be necessary to resolve this issue.

Because vowels are phonologically linked to the consonants that follow them, children may use the following consonant grapheme(s) as a context to help them in pronouncing the vowel grapheme (see also Zinna, Liberman, \& Shankweiler, 1986). This may be especially useful in English, where vowel graphemes often have more than one pronunciation. As a result of this variability, readers in this study and in others (Fowler, Liberman, \& Shankweiler, 1977; Seidenberg, Bruck, Fornarolo, \& Backman, 1986; Shankweiler \& Liberman, 1972; Treiman \& Baron, 1981) had particular difficulty in pronouncing vowels. Even for a vowel such as ai, which is almost always pronounced as /e/, or $e e$, which is almost always pronounced as /i/ (Venezky, 1970), children may learn the vowels' pronunciations in the contexts of common VC units, such as ain and eed. When the same vowels appear in other contexts, such as aip and eeb, children (and even adults) do not always use the standard /e/ and /i/ pronunciations.

Our findings do not support rule-based models of nonword pronunciation (e.g., that of M. Coltheart, 1978) in which rules such as those of Venezky (1970) are used to map graphemes onto phonemes. However, our results fit nicely with Patterson and Morton's (1985) reformulation of the rule-based view. According to Patterson and Morton, readers use two types of rules to assemble the pronunciations of letter strings-rules that involve graphemes and phonemes and rules that involve the "bodies" (or VCs) of printed words and the rimes of spoken words. Chil- 
dren's good performance on nonwords with familiar GPCs can be taken to support the grapheme-phoneme subsystem of Patterson and Morton's model. That VC frequency also affected nonword pronunciation provides evidence for the body subsystem. Our data suggest that word bodies are used by children as well as adults.

Our results can also be incorporated into the class of models known as analogy (e.g., Glushko, 1979) or conspiracy (e.g., Taraban \& McClelland, 1987) models. Seidenberg and McClelland (1989) have recently implemented a model of this kind. These models contain no explicit spelling-sound correspondence rules at any level. They propose, instead, that a nonword activates a neighborhood of real words that share some of its orthographic features. The words' pronunciations are synthesized to yield a pronunciation for the nonword. Most previous studies within the analogy framework have focused on the consistency of the pronunciations of the words in the neighborhood. For example, vaid activates said in addition to maid and paid; the inconsistency of the activated pronunciations causes longer response times and more variable responses to "exception" nonwords like vaid than to "regular" nonwords like tain (Glushko, 1979). Although many studies have examined the effect of neighborhood consistency on pronunciation, only a few have examined the effect of neighborhood size. The findings of Andrews (1989) and McCann and Besner (1987) suggest that adults pronounce words and nonwords (at least nonwords that do not sound like words) from large neighborhoods more rapidly than those from small neighborhoods. Our results are consistent with these findings. Although $\mathrm{H}$ nonwords like tain and $\mathrm{L}$ nonwords like goan are both classified as regular, tain-which belongs to a more densely populated neighborhood than goan-is easier to pronounce.

Within the analogy framework, two questions arise. First, what sorts of orthographic neighborhoods are used in the pronunciation process? Our data suggest that orthographic neighborhoods are based on the ends of words. They consist primarily of words that share the $\mathrm{V}$ and final C of a CVC target. Our findings support Glushko's (1979) original assumption about neighborhoods and are consistent with other data from adults (Taraban \& McClelland, 1987; Treiman and Zukowski, 1988) and children (Goswami, 1986). Our results do not support the definition of orthographic neighborhoods that was proposed by M. Coltheart et al. (1977) and employed by such later researchers as Laxon et al. (1988), Andrews (1989), and McCann and Besner (1987). According to M. Coltheart et al. (1977), words that share the initial $C$ and $V$ of a $\mathrm{CVC}$ nonword should be as influential as words that share the $\mathrm{V}$ and final $\mathrm{C}$.

A second important issue within the analogy framework concerns the relative importance of different words within the orthographic neighborhood. Is the number of words in the neighborhood with a particular pronunciation critical, or is it the frequency of those words that is important? The $\mathrm{H}$ and $\mathrm{L}$ stimuli of our study differed in both respects, since the $\mathrm{H}$ nonwords had more different neighbors and also had a higher summed frequency of neighbors than the L nonwords. In all three experiments, the number of neighbors predicted performance slightly better than did the summed frequency of neighbors. However, the differences were quite small. Additional research is needed to compare the number and frequency of neighbors.

Rule-based models that include units larger than single graphemes and single phonemes are very difficult to distinguish from analogy-based models (see Patterson \& V. Coltheart, 1987). Rather than debate the merits of the two types of models, it may be more fruitful to study issues that arise within both frameworks. The nature of orthographic units is one such issue, which any model of reading or of reading development must address. Our results show that VC units play an important role in nonword pronunciation. They do so for both children and adults.

\section{REFERENCES}

ANDREws, S. (1989). Frequency and neighborhood effects on lexical access: Activation or search? Journal of Experimental Psychology: Learning, Memory, \& Cognition, 15, 802-814.

Carroll, J. B., Davies, P., \& Richman, B. (1971). Word frequency book. New York: American Heritage.

Coltheart, M. (1978). Lexical access in simple reading tasks. In G. Underwood (Ed.), Strategies of information processing (pp. 151216). London: Academic Press.

Coltheart, M., Davelaar, E., Jonasson, J. T., \& Besner, D. (1977). Access to the internal lexicon. In S. Dornic (Ed.), Attention and performance VI (pp. 535-555). Hillsdale, NJ: Erlbaum.

Fowler, C. A., Liberman, I. Y., \& Shankweiler, D. (1977). On interpreting the error pattern in beginning reading. Language \& Speech, 20, 162-173.

FrITH, U. (1985). Beneath the surface of developmental dyslexia. In K. E. Patterson, J. C. Marshall, \& M. Coltheart (Eds.), Surface dyslexia: Neuropsychological and cognitive studies of phonological reading (pp. 301-330). London: Erlbaum.

GLUSHKo, R. J. (1979). The organization and synthesis of orthographic knowledge in reading aloud. Journal of Experimental Psychology: Human Perception \& Performance, 5, 674-691.

Goswami, U. C. (1986). Children's use of analogy in learning to read: A developmental study. Journal of Experimental Child Psychology, 42, 73-83.

Goswami, U., \& Bryant, P. E. (in press). Phonological skills and leaming to read. London: Erlbaum.

JaStak, S., \& WILkInson, G. (1984). The Wide Range Achievement Test-Revised. Wilmington, DE: Jastak Associates.

Laxon, V. J., Coltheart, V., \& Keating, C. (1988). Children find friendly words friendly too: Words with many orthographic neighbours are easier to read and spell. British Journal of Educational Psychology, 58, 103-119.

Marsh, G., Friedman, M., Welch, V., \& Desberg, P. (1981). A cognitive-developmental theory of reading acquisition. In G. E. MacKinnon \& T. G. Waller (Eds.), Reading research: Advances in theory and practice (Vol. 3, pp. 199-221). New York: Academic Press.

MCCANN, R. S., \& BESNER, D. (1987). Reading pseudohomophones: Implications for models of pronunciation assembly and the locus of word frequency effects in naming. Journal of Experimental Psychology: Human Perception \& Performance, 13, 13-24.

Olson, R., WISE, B., ConNers, F., \& RACK, J. (1990). Organization, heritability, and remediation of component word recognition and language skills in disabled readers. In T. H. Carr \& B. A. Levy (Eds.), Reading and its development: Component skills approaches (pp. 261322). New York: Academic Press.

Patterson, K. E., \& Coltheart, V. (1987). Phonological processes 
in reading: A tutorial review. In M. Coltheart (Ed.), Attention and performance XII (pp. 421-447). London: Erlbaum.

Patterson, K. E., \& Morton, J. C. (1985). From orthography to phonology: An attempt at an old interpretation. In K. E. Patterson, J. C. Marshall, \& M. Coltheart (Eds.), Surface dyslexia: Neuropsychological and cognitive studies of phonological reading (pp. 335359). London: Erlbaum

Seidenberg, M. S., Bruck, M., Fornarolo, G., \& Backman, J. (1986). Word recognition skills of poor and disabled readers: Do they necessarily differ? Applied Psycholinguistics, 6, 161-180.

SeidenberG, M. S., \& MCClelland, J. L. (1989). A distributed, developmental model of word recognition and naming. Psychological Review, 96, 523-568.

Shankweiler, D., \& Liberman, I. Y. (1972). Misreading: A search for causes. In J. F. Kavanagh \& I. G. Mattingly (Eds.), Language by ear and by eye: The relationships between speech and reading (pp. 293-317). Cambridge: MIT Press.

Taraban, R., McClelland, J. L. (1987). Conspiracy effects in word pronunciation. Journal of Memory \& Language, 26, 608-631.

Treiman, R. (1988). The intemal structure of the syllable. In G. Carlson \& M. Tanenhaus (Eds.), Linguistic structure in language processing (pp. 27-52). Dordrecht, The Netherlands: Kluwer.

Treiman, R., \& Baron, J. (1981). Segmental analysis ability: Development and relation to reading ability. In G. E. MacKinnon \& T. G. Waller (Eds.), Reading research: Advances in theory and practice (Vol. 3, pp. 159-197). New York: Academic Press.

Treiman, R., \& HirSh-Pasek, K. (1985). Are there qualitative differences in reading behavior between dyslexics and normal readers? Memory \& Cognition, 13, 357-364.

Treiman, R., \& ZuKowsKI, A. (1988). Units in reading and spelling. Journal of Memory \& Language, 27, 466-477.

Treiman, R., Zukowsxi, A. (in press). Levels of phonological awareness. In S. Brady \& D. Shankweiler (Eds.), Phonological processes in literacy. Hillsdale, NJ: Erlbaum.

VENEZKY, R. L. (1970). The structure of English orthography. The Hague: Mouton.

Zinna, D. R., Liberman, I. Y., \& Shankweiler, D. (1986). Children's sensitivity to factors influencing vowel reading. Reading Research Quarterly, 21, 465-480.

\section{NOTE}

1. In addition to counting the number of one-syllable words in the computerized dictionary that contained each VC and CV, we also counted the total number of words-multisyllabic as well as monosyllabic-that contained each unit. According to this measure, too, the VCs in the $\mathrm{H}$ nonwords were much more frequent than the VCs in the $\mathrm{L}$ nonwords. Again, the frequencies of the CVs in the two types of nonwords were very similar.

\section{Appendix}

\section{Nonword and Word Stimuli}

Pronunciations counted as correct for nonwords are indicated in parentheses.

H nonwords. tain (/ten/), goach (/goč/), joal (/ jol/), sug $(/ \mathrm{s} \Lambda \mathrm{g} /)$, vess $(/ \mathrm{ves} /)$, fip $(/ \mathrm{fip} /)$, chail $(/$ čel/ $), \operatorname{pog}(/ \mathrm{pag} /)$, juck $(/ \mathrm{j} \wedge \mathrm{k} /)$, lef $(/ \mathrm{l \varepsilon f} /)$, foud (/faud/), chob (/čab/, vag (/væg/), peef (/pif/), foop (/fup/), hain (/hen/), jub (/jیb/), veed $(/ \mathrm{vid} /)$, cheed $(/$ čid $/)$, lum $\left(/ \mathrm{l}_{\mathrm{m}} /\right)$, meep $(/ \mathrm{mip} /)$, fesh $(/ \mathrm{feš} /)$, losh (/laš/), yoal (/yol/).

L nonwords. goan (/gon/), taich (/teč/), soag (/sog/), jul

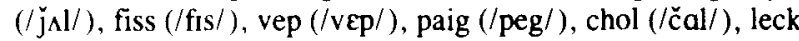
(//عk/), juf $(/ / \mathbf{j} \mathrm{f} /)$, choub (/çaub/), fod $(/ \mathrm{fad} /)$, paf (/pæf/), veeg (/vig/), haip (/hep/), foon (/fun/), vud (/vıd/), jeeb (/jib/), leem $(/ \mathrm{lim} /)$, chud $(/ \check{\mathrm{c}} \wedge \mathrm{d} /)$, fep $(/ \mathrm{fep} /)$, meesh $(/ \mathrm{mis} /)$, yol (/yal/), loash (/loš/).

Words. main, coach, coal, dug, less, ship, tail, dog, truck, clef, loud, job, bag, beef, loop, club, need, drum, deep, fresh, josh, loan, miss, step, Sol, check, God, soon, mud, seem.

Note-/e/ as in bait, /o/ boat, /u/ boot, /e/ bet, /l/ bit, /a/ father, $/ \Lambda /$ but, /au/ bout, $/ \overline{\mathbf{a}} /$ bat, $/ \mathrm{i} /$ beet, $/ \overline{\mathrm{j}} / \underline{\mathrm{J}}$ ill, $/ \overline{\mathrm{c}} / \mathrm{ch}$ ill, $/ \overline{\mathrm{s}} /$ ship.

(Manuscript received February 14, 1990; revision accepted for publication May 8,1990 .) 